\section{The erosive effects of saliva fol- lowing chewing gum on enamel and dentine: an ex vivo study}

\author{
E. M. Paice, ${ }^{1}$ R. W. Vowles, ${ }^{2}$ N. X. West ${ }^{3}$ and S. M. Hooper ${ }^{4}$
}

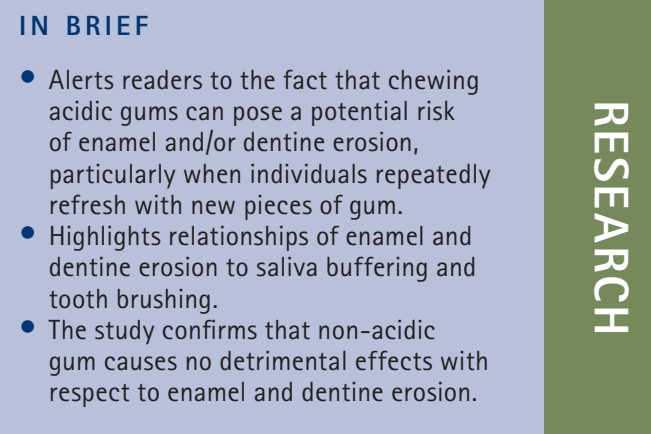

\begin{abstract}
Objectives The primary objective was to determine the erosive effect of expectorated saliva, following chewing acidic gum, on enamel and dentine samples, using a non-acidic gum as a negative control. Secondary objectives were to determine the effect of brushing enamel and dentine samples and the effect of individual saliva $\mathrm{pH}$ and buffering. Design $\mathrm{A}$ single-centre, single-blind, placebo-controlled, two-way crossover study. Setting A clinical trial, involving healthy participants, undertaken at Bristol Dental School and Hospital. Methods Eight healthy participants expectorated saliva onto prepared enamel and dentine samples while chewing gum (strawberry flavoured acidic gum [active] or peppermint flavoured non-acidic gum [control]). Half of the enamel and dentine samples were brushed before measurement by contact profilometry. Main outcome measures Mean enamel and dentine erosion, with and without brushing and the relationship to salivary buffering. Results At 10 days, mean depth of surface loss from dentine samples $(95 \% \mathrm{Cl})$, following chewing of acid-containing gum and subsequent brushing, was $-11.34 \mu \mathrm{m}(2.22 \mu \mathrm{m})$ and from un-brushed dentine samples was $-11.02 \mu \mathrm{m}(1.71 \mu \mathrm{m})$. No significant erosion was noted for other groups. Conclusions Frequent chewers of acid-containing gums are susceptible to dentine erosion even in the presence of good salivary buffering. Enamel erosion was insignificant within the time constraints of the present study but warrants further investigation.
\end{abstract}

\section{INTRODUCTION}

A leading chewing gum manufacturer in the UK has stated that the British currently chew their way through $£ 293$ million worth of chewing gum per year, an increase of 29\% on 2001 figures. ${ }^{1}$ Chewing gum is an increasingly popular habit and has for some years been promoted by the dental profession as being beneficial for the dentition in reducing the risk of caries, ${ }^{2}$ and improving salivary flow. ${ }^{3}$ Medical and dental researchers have considered the benefit of chewing gum as a means to deliver therapeutic agents: for example, calcium carbonate to alleviate heartburn and gastro-oesophageal reflux, ${ }^{4}$ chlorhexidine to reduce plaque deposition ${ }^{5}$ and casein phosphopeptide-amorphous calcium phosphate to remineralise enamel sub-

\footnotetext{
Senior House Officer, ${ }^{2}$ Dental Materials Support Officer, ${ }^{3}$ Professor in Restorative Dentistry, ${ }^{4 *}$ Consultant Senior Lecturer, University of Bristol Dental Hospital, Lower Maudlin Street, Bristol, BS1 2LY

${ }^{*}$ Correspondence to: Miss Susan Hooper

Email: susan.hooper@bristol.ac.uk

Tel: +44 (0)117342 4316
}

\section{Refereed Paper}

Accepted 30 September 2010

DOI: $10.1038 /$ sj.bdj.2010.51

${ }^{\circ}$ British Dental Journal 2010; 210: E3 surface lesions. ${ }^{6}$ The potential benefits have been extensively investigated and reviewed ${ }^{7}$ but literature is lacking in reporting potential detrimental effects of acidic chewing gums in relation to tooth surface loss.

Enamel and dentine erosion in relation to acid foods and beverages, and attempts to reduce such erosion by modification of constituents, is well documented, ${ }^{8,9}$ but research to reduce erosion has not extended to acidic chewing gum. Toothbrushing may exacerbate erosion by abrasion, another process contributing to tooth wear and these processes can be synergistic. Investigations have taken place with respect to combined effects in relation to beverages but not in relation to acidic chewing gum. ${ }^{10,11}$ The act of chewing gum also has the potential to introduce a degree of tooth wear attributable to attrition.

Any suggestion implicating chewing gum as a causative agent of detrimental effects on the dentition warrants further investigation. Interest in the acidity of certain chewing gums and the potential for dental erosion was generated by observation of tooth wear, characteristics of acid erosion, and preferential tooth surface loss affecting the occlusal surfaces of all posterior teeth in a patient admitting to frequent use of flavoured acid chewing gum but with no other relevant medical history or report of gastric erosion.

The primary objective of this paper was to determine the erosive effect of expectorated saliva from human participants following chewing acidic based chewing gum compared to a non-acidic based chewing gum, on enamel and dentine samples. Surface loss was measured by contact profilometry (SF200 surfometer, Planer Products Ltd., Windmill Road, Sunbury-on-Thames, Middlesex TW16 7HD). Secondary objectives were to determine the effect of tooth brushing the enamel and dentine samples immediately following exposure to expectorated saliva following acidic and non-acidic chewing gum and to determine the effect of saliva $\mathrm{pH}$ and salivary buffering.

\section{MATERIALS AND METHODS}

\section{Design}

The trial design was a single-centre, singleblind, randomised two-way crossover study, involving healthy participants, undertaken 
to compare the erosive effect of expectorated saliva following chewing acidic and non-acidic gums on human enamel and dentine specimens.

\section{Subjects}

A sample size of eight healthy participants was chosen based on experience from a previous study. ${ }^{12}$ All participants worked at Bristol Dental Hospital and were 18 years old or older. Inclusion and exclusion criteria for acceptance of subjects in the study were as described and used in previous publications..$^{9,13,14}$ They were all subjects with no medical or pharmaco-therapeutic history, such as acid reflux, which might influence the conduct or outcome of the study. They all underwent a dental screening examination and were caries-free, with good gingival health and no clinical signs or symptoms of pathological tooth surface loss. Ethical approval for the study was granted by the United Bristol Healthcare NHS Trust Ethics Committee. The study was conducted according to the Guidelines for Good Clinical Practice (ICHP) and all data were anonymised for analysis. Subjects received verbal and written information on the study, and gave signed and witnessed consent to participate. The study was blinded to the person responsible for performing the surface profilometry measurements of erosion. An individual not otherwise involved in the study monitored the conduct of the study and the case record forms.

\section{Methods}

Two gums, both market sales leaders, were selected for use in the study: Seriously Strawberry flavoured Hubba Bubba (Wrigley Company, Plymouth, UK) and Extra Peppermint (Wrigley Company, Plymouth, $\mathrm{UK}$ ). The mean $\mathrm{pH}$ (SD) of five samples of Seriously Strawberry was 2.84 (0.04) and that of Extra Peppermint was 6.71 (0.11). The $\mathrm{pH}$ values of these gums are representative of six popular sugar gums ( $\mathrm{pH}$ range 2.703.56) and seven sugar-free gums (pH range 6.58-7.57) investigated for this study.

The enamel and dentine specimens were derived from surgically removed human third molars from 18-year-olds or older individuals of either gender. Sterilisation of the teeth was achieved by soaking in hypochlorite solution for 24 hours with 20,000 ppm available free chlorine. Enamel and dentine specimens were embedded in epoxy resin (Stycast 1266, Emmerson and Cumming Specialist Polymers, Belgium) and polished to produce a flattened window, the specimens having dimensions of $8 \mathrm{~mm} \mathrm{x}$ $5 \mathrm{~mm}$ x $2 \mathrm{~mm}$. Specimens were baselined by contact profilometry. The head unit of the profilometer traversed the specimen at a constant velocity from left to right at a speed of $10 \mathrm{~mm} / \mathrm{min}$. The measuring head was fitted with a diamond stylus of $20 \mu \mathrm{m}$ tip radius. The force of the stylus on the surface varied linearly with deflection at the rate of $8 \mathrm{mg}$ force per micron deflection, the maximum force at $100 \mathrm{~mm}$ being $1.0 \mathrm{~g}$. To be accepted into the study the baseline readings for enamel samples needed to achieve surface profiles of $\pm 0.1 \mathrm{~mm}$, and dentine samples $\pm 0.3 \mathrm{~mm}$. Polyvinyl chloride (PVC) tape was used on the enamel and dentine samples to delineate a zone approximately $1.5 \mathrm{~mm}$ in width for measuring surface loss. The samples were designated by coloured tape to identify whether they were to be brushed or left unbrushed. Each enamel and dentine sample was identified with a unique number on the back using a permanent pen and assigned to a specific subject participating in the study. Two perspex strips, each with four mounted samples (two enamel and two dentine), were placed on the base of a small container in readiness for collection of saliva expectorant by a specified subject. One perspex strip held the samples for brushing and the other the samples to be withheld from brushing.

Before each attendance subjects were asked to abstain from drinking or eating for one hour. They attended four times a day for ten successive study days for each gum according to study randomisation and were supervised throughout each attendance. Subjects attended at the same times each day: $9.00 \mathrm{am}, 11.00 \mathrm{am}, 1.00 \mathrm{pm}$ and $3.00 \mathrm{pm}( \pm 30$ minutes for each of these appointments). Each time subjects attended the Clinical Trials Unit they confirmed they had abstained from drinking or eating during the previous hour and they then chewed three pieces of gum consecutively, each one for four minutes (total 12 minutes). They spat any saliva generated at 30-second intervals onto the enamel and dentine samples held in a plastic container. Subjects gently agitated the container to ensure saliva remained on the exposed enamel and dentine windows of each sample. After four minutes the samples were transferred to a new container and the subject commenced chewing a fresh piece of gum. This process was repeated for the final piece of gum. On completion of each 12-minute chewing cycle, the samples were rinsed with de-ionised water.

After each visit, site personnel drybrushed the two designated enamel and two designated dentine samples for each subject with a powered toothbrush (Braun Oral B advanced power 900 series fitted with an EB17 Flexisoft head; Gillette UK, Middlesex) for 30 seconds. The brushed and unbrushed samples were then placed in a subject-designated container with cotton wool rolls dampened with Volvic ${ }^{\circledR}$ water.

At the start and end of each treatment day, plus before and after taking the profilometry measurements, the enamel and dentine samples were disinfected by dipping in $0.2 \% \mathrm{w} / \mathrm{v}$ chlorhexidine gluconate, Corsodyl ${ }^{\circledR}$ mouthrinse (GlaxoSmithKline, Brentford, UK) for three minutes. The samples were then rinsed in $200 \mathrm{mls}$ of mineral water, Volvic ${ }^{\circledR}$ (Danone Waters, London, $\mathrm{UK})$, in a $500 \mathrm{ml}$ beaker.

On days 5 and 10 all enamel and dentine samples, brushed and unbrushed, were examined by profilometry for surface loss by a trained and experienced profilometry operator. ${ }^{11,12,15-17}$ Each time the profilometer was turned on for a measuring session, a flat enamel calibration sample was measured to ensure two consecutive readings were within $\pm 0.1 \mu \mathrm{m}$. The surface profiles of the enamel and dentine samples preand post-treatment identified the amount of tooth surface lost in microns. All samples were read twice and an average reading was used for analysis.

\section{Salivary buffering capacity and change in $\mathrm{pH}$ during chewing}

Each subject was also asked to attend on two separate occasions for the purpose of investigating the buffering capacity of their saliva and its change in $\mathrm{pH}$ during chewing the test products. All volunteers attended at $9.00 \mathrm{am}$ ( \pm 30 minutes) consistent with the first daily attendance for the main study investigating the erosive effects of saliva following chewing gum on enamel and dentine and subsequent brushing. The buffering capacity for each subject was established by measuring the $\mathrm{pH}$ of a freshly supplied $3 \mathrm{ml}$ unstimulated saliva sample using a calibrated glassbodied combination $\mathrm{pH}$ reference electrode (Jenway, Dunmow, UK) and re-measuring 
Table 1 Summary of enamel and dentine loss at days 5 and 10 post-exposure to saliva following chewing gum

\begin{tabular}{l|l|l|l|l}
\hline Sample & Day & Test group & $\begin{array}{l}\text { Mean depth }(\mu \mathrm{m}) \mathrm{N}=8 \text { for } \\
\text { HB, N = 7 for EP }\end{array}$ & $\begin{array}{l}95 \% \text { confidence } \\
\text { interval }(\mu \mathrm{m})\end{array}$ \\
\hline Enamel & 5 & HB brushed & -0.11 & 0.13 \\
\hline Enamel & 5 & HB unbrushed & -0.15 & 0.17 \\
\hline Enamel & 5 & EP brushed & -0.02 & 0.05 \\
\hline Enamel & 5 & EP unbrushed & -0.02 & 0.04 \\
\hline Enamel & 10 & HB brushed & -0.33 & 0.49 \\
\hline Enamel & 10 & HB unbrushed & -0.16 & 0.18 \\
\hline Enamel & 10 & EP brushed & -0.03 & 0.03 \\
\hline Enamel & 10 & EP unbrushed & -0.03 & 0.04 \\
\hline Dentine & 5 & HB brushed & -6.88 & 1.33 \\
\hline Dentine & 5 & HB unbrushed & -6.74 & 1.30 \\
\hline Dentine & 5 & EP brushed & -0.10 & 0.12 \\
\hline Dentine & 5 & EP unbrushed & 0.02 & 0.19 \\
\hline Dentine & 10 & HB brushed & -11.34 & 2.22 \\
\hline Dentine & 10 & HB unbrushed & -11.02 & 1.71 \\
\hline Dentine & 10 & EP brushed & -0.06 & 0.13 \\
\hline Dentine & 10 & EP unbrushed & 0.02 & 0.15 \\
\hline HB: Seriously Strawberry Hubba Bubba; EP: Extra Peppermint; Subject 2 excluded from Extra Peppermint leg & \\
\hline
\end{tabular}

the $\mathrm{pH}$ after additions of $200 \mu \mathrm{l} 0.05 \mathrm{M}$ hydrochloric acid ( $\mathrm{HCl})$ until $2000 \mu \mathrm{l} \mathrm{HCl}$ had been added in total.

The change in $\mathrm{pH}$ during chewing the test products was measured by first measuring the $\mathrm{pH}$ of a freshly supplied $3 \mathrm{ml}$ unstimulated saliva sample from each subject. Subjects were then asked to chew a single piece of one of the test formulations for 30 minutes. During chewing, subjects were asked to spit (when they would normally swallow) all saliva into sequential small bottles as per the following regimen: during the first minute into bottle 1, during the following two minutes into bottle 2, during the next two minutes into bottle 3. During the remaining 25 minutes they were asked to spit into bottles $4-8$, moving to a new bottle every five minutes. This regimen was devised as more saliva is generated during the first five minutes of chewing gum. The $\mathrm{pH}$ was recorded twice for each sample and an average reading used for analysis.

\section{Statistics}

A paired t-test was used to compare the two gums selected for the study. Further analysis on the erosion was undertaken using the Kruskal-Wallis Test. Mean erosion, at the
95\% confidence level, was established for each participant and ranked for comparison with salivary $\mathrm{pH}$ and buffering.

\section{Outcome measures}

The mean enamel and dentine tooth surface loss, with and without subsequent brushing, for individual subjects, and the relationship of erosion to salivary $\mathrm{pH}$ and buffering.

\section{RESULTS}

Eight healthy participants, five females and three males, completed the study having a mean age of 36.5 years (range 25-63.5 years).

The differences between the baseline readings and the readings taken at day 5 and day 10 were calculated for each participant and then averaged to provide a mean erosion figure with a 95\% confidence interval (CI) for each group of samples. Samples were grouped for day 5 and day 10 readings by

1. type of gum chewed, Hubba Bubba or Extra Peppermint

2. enamel or dentine sample

3. brushed or unbrushed sample (see Table 1).

Each participant's dentine samples were shown to have undergone considerable erosion after exposure to saliva having chewed Seriously Strawberry Hubba Bubba chewing gum. After five days and ten days brushed dentine samples demonstrated greatest surface loss at $-6.88 \mu \mathrm{ms}$ (CI $1.32 \mu \mathrm{ms}$ ) and $-11.34 \mu \mathrm{ms}$ (CI $2.22 \mu \mathrm{ms}$ ). There was strong statistical evidence (Kruskal-Wallis) to demonstrate a difference ( $\mathrm{p}<0.0001)$ between all Hubba Bubba and Extra Peppermint groups subjected to the same regimens.

When brushed and unbrushed samples in otherwise similar groups were compared statistical evidence only identified a significant difference ( $\mathrm{p}<0.05$ ) after 10 days, between brushed and un-brushed dentine samples exposed to Extra Peppermint. In these groups the surface loss was minimal, between $-0.10 \mu \mathrm{ms}$ (CI $0.12 \mu \mathrm{ms}$ ) and $+0.2 \mu \mathrm{ms}$ (CI $0.19 \mu \mathrm{ms}$ ) taking consideration of readings at both day 5 and day 10 respectively. Statistical evidence did not identify significant differences between any other groups when comparing brushed and unbrushed samples.

\section{Salivary buffering capacity and change in $\mathrm{pH}$ during chewing gum}

Combining erosion results for brushed and unbrushed samples, correlation coefficients between rankings for tooth surface loss by subject and amount of acid required to decrease the $\mathrm{pH}$ by one unit were good for Hubba Bubba enamel (0.93) and satisfactory for dentine (0.64) but were poor for Extra Peppermint enamel (0.20) and dentine (0.25) respectively.

The amount of 0.05M hydrochloric acid ( $\mathrm{HCl})$ added to a $3 \mathrm{ml}$ unstimulated saliva sample from each subject to lower the $\mathrm{pH}$ by one unit was used to rank the salivary buffering capacity of each subject. Subjects 1 and 2 required the least $\mathrm{HCl}$ addition (0.04 ml, $0.08 \mathrm{ml}$ respectively) while subjects 4 and 5 required the greatest $(0.24 \mathrm{ml}$, $0.37 \mathrm{ml}$ respectively) [see Table 2 for ranking]. Subjects 4 and 5 also required the most $\mathrm{HCl}$ addition ( $0.4 \mathrm{ml}$ and $0.5 \mathrm{ml}$ respectively) to reduce the $\mathrm{pH}$ of the saliva samples below the critical $\mathrm{pH}$ of 5.5.

The lowest recorded $\mathrm{pH}$ following chewing acidic gum for each subject ranged from 3.52 to 4.20 . Figures 1 and 2 illustrate the speed of neutralisation of the saliva after chewing Extra Peppermint and Seriously Strawberry Hubba Bubba respectively. After chewing Seriously Strawberry Hubba 


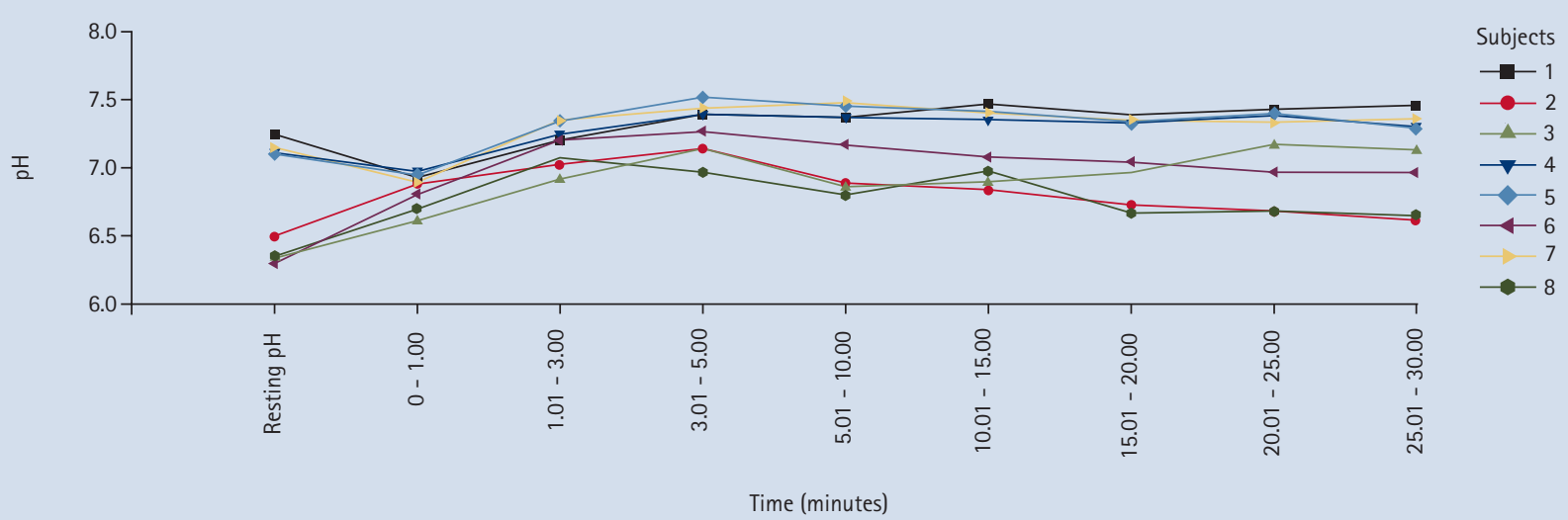

Fig. 1 Speed of neutralisation of the oral cavity after chewing Extra Peppermint gum

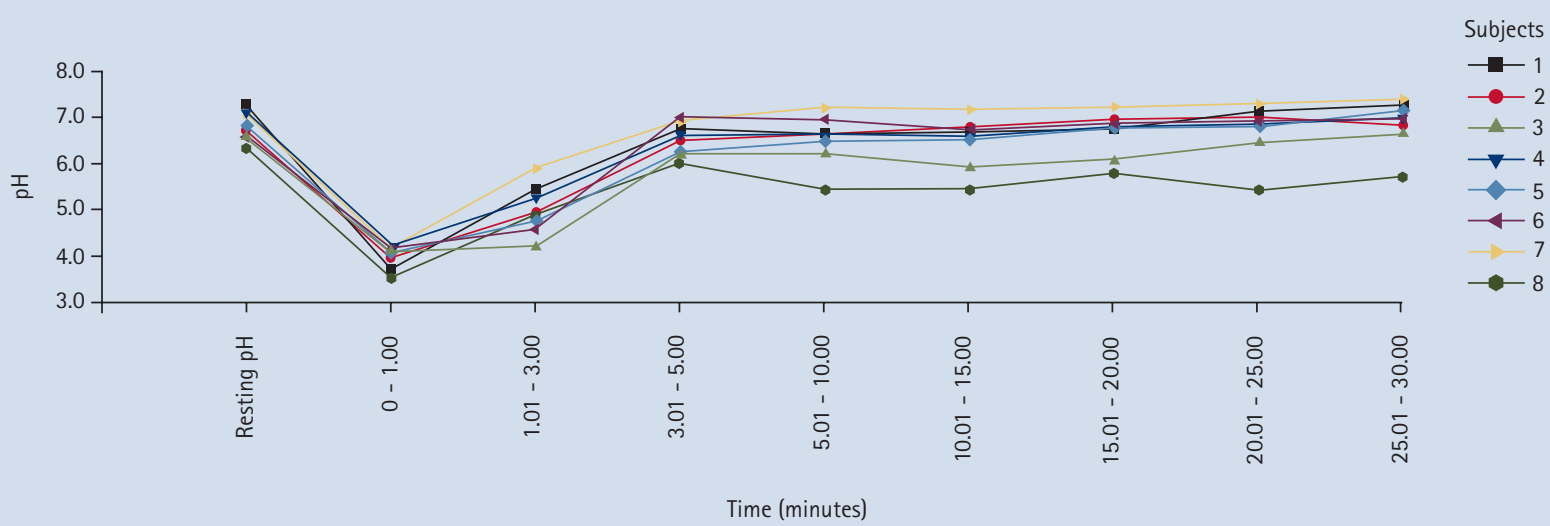

Fig. 2 Speed of neutralisation of the oral cavity after chewing Seriously Strawberry Hubba Bubba gum

Bubba for one minute the mean salivary $\mathrm{pH}$ of all subjects was 3.98, whereas for Extra Peppermint the mean salivary $\mathrm{pH}$ of all subjects was 6.80. However, the recovery in $\mathrm{pH}$ of saliva while chewing Seriously Strawberry Hubba Bubba was rapid; after three minutes the mean $\mathrm{pH}$ was 4.99 (Extra Peppermint $\mathrm{pH}$ 7.02) and after five minutes the mean $\mathrm{pH}$ was 6.53 , a level approaching 7.27 , the mean salivary $\mathrm{pH}$ of subjects chewing Extra Peppermint.

Subject ranking was also undertaken with respect to time taken for saliva $\mathrm{pH}$ to return to resting levels (range 3 mins-30 mins) although within 5 mins all subjects had a saliva $\mathrm{pH}$ above the critical $\mathrm{pH}$ of $5.5 \mathrm{pH}$ range 5.99-7.00). Only one subject had a $\mathrm{pH}$ above the critical $\mathrm{pH}$ after 3 minutes.

\section{DISCUSSION}

Erosive tooth wear is an increasingly important factor when considering the long-term health of the dentition and it is well established that the aetiology is multifactorial $^{(18,19)}$. Chewing gum adds a behavioural component which, with acidic gums, can

\begin{tabular}{|c|c|c|c|}
\hline $\begin{array}{l}\text { Dentine erosion } \\
\text { (brushed and unbrushed): } \\
\text { most to least erosion }\end{array}$ & $\begin{array}{l}\text { Salivary titration drop } \\
\text { in } \mathrm{pH} \text { by } 1 \text { unit: least to } \\
\text { most } \mathrm{HCl} \text { added }\end{array}$ & $\begin{array}{l}\text { Lowest } \mathrm{pH} \text { recorded } \\
\text { following chewing: } \\
\text { lowest to highest } \mathrm{pH}\end{array}$ & $\begin{array}{l}\text { Time taken for saliva } \\
\text { to return to resting } \mathrm{pH} \text { : } \\
\text { slowest to quickest time }\end{array}$ \\
\hline 1 & 1 & 8 & 4,8 \\
\hline 2 & 2 & 1 & \\
\hline 4 & 8 & 6 & 1,3 \\
\hline 8 & 6 & 2 & \\
\hline 6 & 3 & 5 & 5 \\
\hline 5 & 7 & 3 & 2 \\
\hline 3 & 4 & 4 & 7 \\
\hline 7 & 5 & 7 & 6 \\
\hline
\end{tabular}

compound erosive tooth surface loss by introducing a component of attrition. In the presence of saliva, chemical and biological issues further compound identification of the causative factors. This study sought to examine, ex vivo, the interaction of these latter effects. Chewing gum for 20 minutes has been shown to increase both salivary flow rate and salivary $\mathrm{pH}$ and has been deemed beneficial to oral and dental health with a potential to promote enamel remineralisation. ${ }^{5,20}$ There is sparse evidence in the literature to suggest any chewing gums contribute to enamel or dentine erosion although some evidence has related to the potential for plaque $\mathrm{pH}$ to remain low 
potentially affecting caries susceptibility. Low plaque $\mathrm{pH}$ levels occur during and after the chewing of sucrose (acidic)-containing chewing gum, despite the masticatory stimulation of saliva. ${ }^{5,21}$ Although the present study indicated a rapid rise in salivary $\mathrm{pH}$ after chewing Seriously Strawberry Hubba Bubba, repeated chewing with frequent refreshment of new gum could potentially be very damaging. Subjects participating in the study stated that the flavour from the Seriously Strawberry Hubba Bubba rapidly diminished within minutes of chewing. Individuals enjoying these flavoured gums are more likely to habitually replace gum.

The $\mathrm{pH}$ of the Extra Peppermint gum in solution was 6.71. As this value sits above the critical $\mathrm{pH}$, no enamel or dentine erosion was expected. The main artificial sweetener found in Wrigley's Extra Peppermint is xylitol, which is non-acidogenic. ${ }^{21}$ Xylitol is not fermented to form acids at the rate recorded for conventional mono- and disaccharides for example, glucose (present in Seriously Strawberry Hubba Bubba) and sucrose which is also found in many other sugar-containing (acidic) chewing gums. ${ }^{2}$ In this study, little or no fall in salivary pH resulted when Extra Peppermint gum was chewed (see Figure 1) when compared with chewing Seriously Strawberry Hubba Bubba (see Figure 2). The pH of the Seriously Strawberry Hubba Bubba gum in solution was 2.84. However, despite a rapid fall in $\mathrm{pH}$ of expectorated saliva within one minute of chewing Seriously Strawberry Hubba Bubba, this gum similarly increased salivary flow rate. Refreshing gum, by regularly chewing a new piece, is potentially very damaging. In this study, replacement of gum every four minutes resulted in marked dentine erosion. The time constraints of the present study are probably responsible for the limited enamel erosion seen. The duration of contact has been shown to be of importance. ${ }^{22}$ If the strengths and frequencies of acidic challenges are such that the process of repair is unable to take place then erosion of tooth tissue is expected to occur.

The present study demonstrated no clinical differences between the amounts of tooth surface loss seen on the unbrushed samples compared with the brushed samples. This was a surprising result but may be attributable to the brushing taking place dry. Previous work has stated that a toothbrush alone (that is, without paste) is unlikely to cause significant abrasion to dentine. ${ }^{23}$ A more clinically relevant approach may have been to have brushed with toothpaste. There is discussion in the literature with respect to the effect of brushing eroded surfaces. An increased susceptibility to erosion with brushing has been shown, ${ }^{24}$ while other studies do not support the notion that brushing increases substance loss of eroded dentine. ${ }^{25,26}$ When comparisons are made with respect to the use of fluoride or non-fluoride pastes while brushing eroded tooth surfaces, the nonfluoride paste was favourable..$^{27,28}$

The individual saliva buffering identified that the subjects requiring the least amounts of acid to reach the critical $\mathrm{pH}$ were relatively consistent with ranking of their dentine erosion occurring after chewing Seriously Strawberry Hubba Bubba with the exception of one subject [subject 4] (Table 2). There was less consistency when comparing the dentine erosion ranking of the subjects to the time taken for saliva to return to resting $\mathrm{pH}$ after chewing Seriously Strawberry Hubba Bubba or the lowest $\mathrm{pH}$ recorded while chewing.

Enamel erosion was insignificant with Seriously Strawberry Hubba Bubba within the time constraints of the present study. Further studies are warranted to examine this more fully in the light of the popularity of the gums with adolescents and young adults.

\section{CONCLUSIONS}

The study concluded that Seriously Strawberry Hubba Bubba contributed to significant erosion of human dentine (mean -11.34 $\mu \mathrm{m}$ brushed, -11.02 $\mu \mathrm{m}$ unbrushed) when chewed for short periods of time with frequent intake of new pieces of gum, even in the presence of good salivary buffering.

1. The Wrigley Company Ltd. Your guide to the benefits of chewing. http://www.wrigley.com/uk/ images/benefits_of_chewing.pdf. Accessed 06 February 2011.

2. Edgar W M. Sugar substitutes, chewing gum and dental caries-a review. Br Dent J 1998; 184: 29-32.

3. Addy M, Perriam E, Sterry A. Effects of sugared and sugar-free chewing gum on the accumulation of plaque and debris on the teeth. J Clin Periodontol 1982; 9: 346-354

4. Collings K L, Rodriguez-Stanley S, Proskin H M, Robinson M, Miner P B Jr. Clinical effectiveness of a new antacid chewing gum on heartburn and oesophageal pH control. Aliment Pharmacol Ther 2002; 16: 2029-2035.

5. Imfeld T. Chewing gum-facts and fiction: a review of gum-chewing and oral health. Crit Rev Oral Biol Med 1999; 10: 405-419.

6. lijima Y, Cai F, Shen P, Walker G, Reynolds C, Reynolds $E C$. Acid resistance of enamel subsurface lesions remineralized by a sugar-free chewing gum containing casein phosphopeptide-amorphous calcium phosphate. Caries Res 2004; 38: 551-556.

7. Ly K A, Milgrom P, Rothen M. The potential of dentalprotective chewing gum in oral health interventions. J Am Dent Assoc 2008; 139: 553-563.

8. Bartlett D W, Bureau G P, Anggiansah A. Evaluation of the $\mathrm{pH}$ of a new carbonated soft drink beverage: an in vivo investigation. J Prosthodont 2003; 12: 21-25.

9. Hughes J A, West N X, Parker D M, Newcombe R G, Addy M. Development and evaluation of a low erosive blackcurrant juice drink. 3. Final drink and concentrate, formulae comparisons in situ and overview of the concept. J Dent 1999: 27: 345-350.

10. Addy $M$, Hughes J, Pickles M J, Joiner A, Huntington E. Development of a method in situ to study toothpaste abrasion of dentine. Comparison of 2 products. J Clin Periodonto/ 2002; 29: 896-900.

11. Hooper S, West N X, Pickles M J, Joiner A, Newcombe $R$ G, Addy $M$. Investigation of erosion and abrasion on enamel and dentine: a model in situ using toothpastes of different abrasivity. J Clin Periodontol 2003; 30: 802-808.

12. Hooper S M, Hughes J A, Newcombe R G, Addy M, West N X. A methodology for testing the erosive potential of sports drinks. J Dent 2005; 33: 343-348.

13. Hughes J A, West N X, Parker D M, Newcombe R G, Addy M. Development and evaluation of a low erosive blackcurrant juice drink in vitro and in situ. 1. Comparison with orange juice. J Dent 1999; 27: 285-289.

14. West N X, Hughes J A, Parker D M, Newcombe R G, Addy M. Development and evaluation of a low erosive blackcurrant juice drink. 2. Comparison with a conventional blackcurrant juice drink and orange juice J Dent 1999; 27: 341-344.

15. Hooper S M, Newcombe R G, Faller R, Eversole S, Addy $M$, West N X. The protective effects of toothpaste against erosion by orange juice: studies in situ and in vitro. J Dent 2007; 35: 476-481.

16. Hooper $S$, West N X, Sharif $N$ et al. A comparison of enamel erosion by a new sports drink compared to two proprietary products: a controlled, crossover study in situ. J Dent 2004; 32: 541-545.

17. Hooper S, Hughes J, Parker D et al. A clinical study in situ to assess the effect of a food approved polymer on the erosion potential of drinks. J Dent 2007; 35: 541-546.

18. Lussi A, Hellwig E, Ganss C, Jaeggi T. Buonocore Memorial Lecture. Dental erosion. Oper Dent 2009; 34: 251-262.

19. Barbour $M E$, Rees $G D$. The role of erosion, abrasion and attrition in tooth wear. J Clin Dent 2006; 17: 88-93.

20. Polland K E, Higgins F, Orchardson R. Salivary flow rate and $\mathrm{pH}$ during prolonged gum chewing in humans. J Oral Rehabil 2003; 30: 861-865.

21. Rugg-Gunn A J, Edgar W M, Jenkins G N. The effect of eating some British snacks upon the $\mathrm{pH}$ of human dental plaque. BrDent J 1978; 145: 95-100.

22. Lussi A, Jaeggi T, Zero D. The role of diet in the aetiology of dental erosion. Caries Res 2004; 38 Suppl $1: 34-44$.

23. Absi E G, Addy M, Adams D. Dentine hypersensitivitythe effect of toothbrushing and dietary compounds on dentine in vitro: an SEM study. J Oral Rehabil 1992; 19: 101-110.

24. Kelly M P, Smith B G. The effect of remineralizing solutions on tooth wear in vitro. J Dent 1988; 16: 147-149.

25. Ganss C, Schlueter N, Hardt M, von Hinckeldey J, Klimek J. Effects of toothbrushing on eroded dentine. Eur J Oral Sci 2007: 115: 390-396.

26. Ganss C, Hardt M, Blazek D, Klimek J, Schlueter N. Effects of toothbrushing force on the mineral content and demineralized organic matrix of eroded dentine. Eur J Oral Sci 2009; 117: 255-260.

27. Bartlett D W, Smith B G, Wilson R F. Comparison of the effect of fluoride and non-fluoride toothpaste on tooth wear in vitro and the influence of ename fluoride concentration and hardness of enamel. Br Dent J 1994; 176: 346-348.

28. Lussi A, Jaeggi T. Erosion-diagnosis and risk factors. Clin Oral Investig 2008; 12 Suppl 1: S5-13. 